\title{
A Case of Myoclonus-dystonia Diagnosed as Tourette Syndrome
}

\author{
Gregory Hosier', Roger McKelvey² \\ 'Class of 2016, Faculty of Medicine, Dalhousie University \\ ${ }^{2}$ Division of Neurology, Department of Medicine, Dalhousie University
}

\begin{abstract}
Myoclonus dystonia (M-D) is a rare movement disorder characterized by a combination of myoclonic jerks and mild dystonia typically beginning before age 20. M-D is caused by mutations in the SGCE gene in $36 \%$ of cases. We report a patient with genetically confirmed M-D who was initially diagnosed with Tourette syndrome (TS) for 15 years. Myoclonic jerks are distinguished from tics seen in Tourette syndrome in that they are not suppressed by conscious effort, are not preceded by an urge to carry out the movement, can interfere with voluntary movement, and are suppressed by alcohol intake. Conversely, tics seen in Tourette syndrome can be suppressed with conscious effort, are preceded by an urge to tic, often have a verbal component, do not normally interfere with voluntary movement, and are not reduced by alcohol. Although M-D is rare, it must be considered in patients with early onset myoclonus and dystonia, especially in cases with a positive family history.
\end{abstract}

\section{Case Presentation}

A 28-year-old, right-handed male presented with abnormal jerky movements of the head, neck, and upper extremities since age thirteen. These movements were made worse by stress, and became particularly aggravated by writing with his left hand. Further questioning elicited that the jerks were decreased by alcohol intake, not suppressed by conscious effort, and not preceded by an urge to carry out the movement. The patient reported symptoms of obsessive-compulsive disorder, depression, social anxiety, and difficulty sleeping and was previously diagnosed with TS when the movements began. Questioning regarding family history revealed the presence of a similar movement disorder in his father.

Neurological examination revealed intermittent, variable, high frequency myoclonic jerks of the head, neck, and upper extremities, as well as mild dystonia of the neck and upper extremities. His head tended to turn and tilt to the left. He tended to hold his left hand in a dystonic posture, particularly when walking. He had intermittent facial myoclonus and the rest of the cranial nerves were normal. He was somewhat poorly coordinated with tandem gait but toe tapping was adequately done. Finger movements were somewhat clumsy for a person of his age and myoclonus interfered with fine motor coordination. Romberg test was negative and Babinski reflex was absent and there were no signs of ataxia. Muscle tone, strength, and bulk were normal. Sensations and reflexes were normal.

On the basis of these findings, genetic testing for Myoclonus-dystonia (M-D) was carried out by PCR amplification and sequencing of the SGCE gene. The patient was found to be heterozygous for a nonsense mutation in exon 3 of the SGCE gene (c.304C>T), a mutation that has been clearly documented as causative for M-D. ${ }^{1}$ The patient was counseled on the hereditary nature of this disorder. Symptomatic treatment with sodium valproate $250 \mathrm{mg}$ two times daily and clonazepam $0.5 \mathrm{mg}$ two times daily was initiated. He did not find these medications to be effective for his myoclonus and dystonia, but found that the clonazepam did improve his sleeping. Sodium valproate was tapered off and he was continued on clonazepam to help with sleeping. The patient was counseled on available symptomatic treatments and chose to initiate the antidepressant paroxetine to help with symptoms of myoclonus and dystonia, as well as depression.

\section{Discussion}

M-D is a rare movement disorder characterized by a combination of myoclonic jerks, usually in the arms and axial muscles, and mild dystonia, in the head and upper extremities. ${ }^{2}$ Diagnostic criteria for M-D includes onset before 20 years of age, myoclonus predominating in the upper body, positive family history for M-D with paternal transmission, normal brain MRI, and exclusion of additional neurological features such as cerebellar ataxia, spasticity, and dementia. ${ }^{2}$ Elevated rates of psychiatric disturbances, including obsessivecompulsive disorder, depression, social anxiety, and panic disorders, have been reported in patients with M-D. ${ }^{3}$ Patients with M-D often have a drastic reduction of myoclonus in response to alcohol ingestion. ${ }^{2}$ There are no prevalence studies of M-D due to its rarity, 
however, cases have been identified in families of various regions including Europe, South America, North America, and Asia. ${ }^{2}$

M-D is an autosomal dominant disorder with reduced penetrance attributed to maternal imprinting., ${ }^{4,5}$ Maternal inheritance has a penetrance of 10-15\%, while paternal inheritance results in full penetrance. ${ }^{4,5}$ The SGCE gene was identified in 1997 and linked to M-D in 2001. ${ }^{6}$ Gene testing in 25 patients diagnosed clinically with definite or probable M-D showed that mutations in the SGCE gene are present in 36\% of patients with M-D. ${ }^{1}$ The SGCE gene encodes $\varepsilon$-sarcoglycan protein, a transmembrane protein that is believed to help link the cytoskeleton to the extracellular matrix. Genetic mutations in the D2 dopamine receptor gene (DRD2) and TOR1A gene have been identified in patients with $M-D$, however, it is unclear whether these mutations contribute to disease phenotype as mutations in the SGCE gene were also identified in these patients. ${ }^{7-9}$ Genetic mutations in the DTY15 gene locus were identified in a Canadian family with M-D in the absence of mutations in SGCE, indicating that mutations in DYT15 gene locus alone are sufficient to cause M-D. ${ }^{10,11}$ Spontaneous cases of M-D have also been reported. ${ }^{12}$ Although management of M-D is not greatly changed based on the results of genetic testing, genetic testing is useful to confirm a diagnosis of M-D, allow for genetic counseling, and to provide insight into the clinical spectrum of $M-D$, as M-D patients with mutations in the SGCE gene are more likely to experience psychiatric impairments (obsessive-compulsive disorder, depression, and social anxiety) and mild impairment of executive cognitive function. ${ }^{3}$

The pathophysiology of M-D is not well understood. M-D is believed to be of a subcortical origin due to the absence of cortical correlates of myoclonic jerks. ${ }^{2}$ It has been proposed that the M-D phenotype occurs due to increased synchronization of neuronal activity in the basal ganglia network. ${ }^{13}$

There are several features that can be used clinically to differentiate M-D from TS. Myoclonic jerks are lightning-like movements involving the head, neck and upper limbs, they cannot be consciously suppressed, are often made worse by certain actions (e.g. writing with the left hand in this case), can interfere with voluntary movement, and are reduced by alcohol intake. Conversely, tics seen in Tourette syndrome (TS) can be suppressed with conscious effort, are preceded by an urge to tic, do not interfere with voluntary movement, and are not reduced by alcohol intake (Figure 1). ${ }^{14}$ Tourette syndrome symptomology also differs from M-D in that verbal tics are present, symptoms tend to remit by adulthood, and there is a complex inheritance pattern. In M-D verbal tics are absent, symptoms continue into adulthood, and inheritance is autosomal dominant with reduced penetrance (Figure 1). ${ }^{14}$ Features that favoured a clinical diagnosis of $M-D$ in this case were the nature of the movements (fast jerks

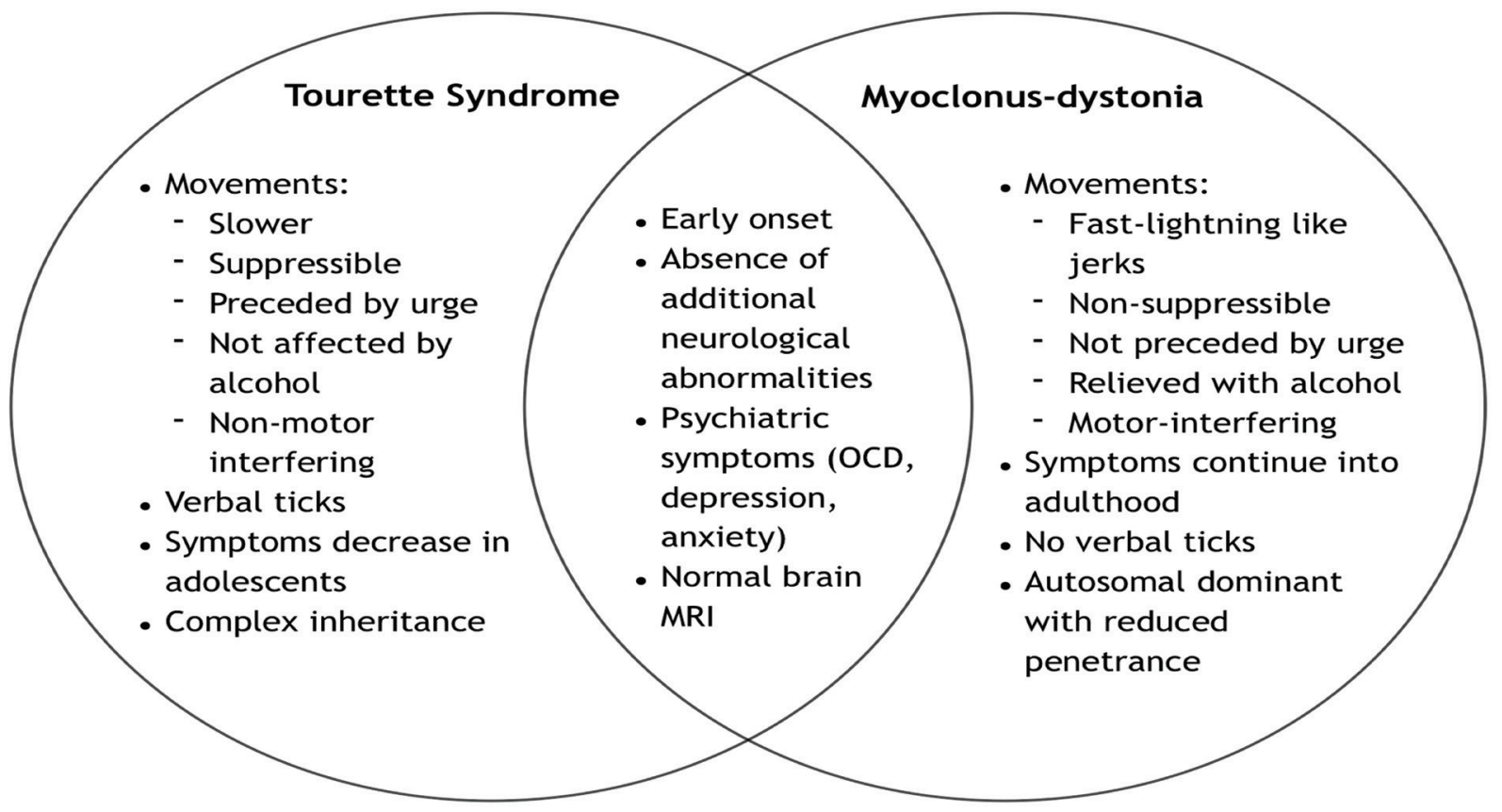

Figure 1. Differential and common features of Myoclonus-dystonia and Tourette syndrome. 
involving head and upper extremities, made worse by and interfered with writing with non-dominant hand, and reduced by alcohol intake), absence of verbal tics, positive family history for a similar movement disorder with paternal transmission, and symptoms continuing into adulthood.

Conditions that include myoclonus as a major component may be considered in the differential diagnosis of M-D, but certain characteristics of the myoclonus are usually different and additional neurological manifestations may be present. $^{2}$ For example progressive myoclonus epilepsy may present with myoclonus as a prominent clinical feature, however, this is usually accompanied by grand mal seizures. ${ }^{15}$ Myoclonus may be a prominent feature of other primary dystonias, including DYT1 ${ }^{16,17}$ and dopa-responsive dystonia ${ }^{18,19}$ in rare cases. Vitamin $\mathrm{E}$ deficiency has also been reported to cause myoclonus and dystonia, though it is usually accompanied by ataxia. ${ }^{20}$ It is important to rule out vitamin E deficiency, as this is easily treatable.

A variety of symptomatic treatments have been tried for M-D with limited success. There are case reports of benzodiazepines, anticholinergic drugs, neuroleptics (tetrabenazine and haloperidol) and serotonergic agents (tryptophan, paroxetine, and venlafaxine) occasionally improving both myoclonus and dystonia. ${ }^{2,21,22}$ There are case reports of antiepileptic drugs, such as sodium valproate, levetiracetam, barbiturates, primidone, piracetam, carbamazepine, and gabapentin, improving myoclonus. ${ }^{2}$ Deep brain stimulation of the internal globus pallidus has been shown to be safe and effective at improving myoclonus and dystonia in a small number of refractory patients. ${ }^{23-25}$ A number of therapies used for $\mathrm{M}-\mathrm{D}$, including the anticonvulsant drugs levetiracetam and topiramate, can cause depression. We did not pursue these therapies as they could potentially worsen our patient's depression. Instead we chose to initiate the anti-depressant paroxetine to help with symptoms of myoclonus and dystonia, as well as depression.

\section{Conclusion}

This is a case of M-D diagnosed as Tourette syndrome for 15 years that illustrates the importance of revisiting an initial diagnosis with the aid of genetic testing. This is similar to a recent case in which M-D was misdiagnosed as Tourette syndrome ${ }^{26}$, indicating that, although M-D is rare, it must be considered in patients with early onset myoclonus and dystonia, especially in cases with a positive family history.

\section{Refrences}

1. Grünewald A, Djarmati A, Lohmann-Hedrich K, Farrell K, Zeller JA, Allert N, et al. Myoclonus-dystonia: significance of large SGCE deletions. Hum Mutat 2008;29(2):331-2.

2. Kinugawa K, Vidailhet M, Clot F, Apartis E, Grabli D, Roze E. Myoclonus-dystonia: an update. Mov Disord 2009;24(4):479-89.

3. Van Tricht MJ, Dreissen YEM, Cath D, Dijk JM, Contarino MF, Van der Salm SM, et al. Cognition and psychopathology in myoclonusdystonia. J Neurol Neurosurg Psychiatry 2012;83(8):814-20.

4. Müller B, Hedrich K, Kock N, Dragasevic N, Svetel M, Garrels J, et al. Evidence that paternal expression of the epsilon-sarcoglycan gene accounts for reduced penetrance in myoclonus-dystonia. Am J Hum Genet 2002;71(6):1303-11.

5. Grabowski M, Zimprich A, Lorenz-Depiereux B, Kalscheuer V, Asmus F, Gasser T, et al. The epsilon-sarcoglycan gene (SGCE), mutated in myoclonus-dystonia syndrome, is maternally imprinted. Eur J Hum Genet 2003;11(2):138-44.

6. Zimprich A, Grabowski M, Asmus F, Naumann M, Berg D, Bertram $\mathrm{M}$, et al. Mutations in the gene encoding epsilonsarcoglycan cause myoclonus-dystonia syndrome. Nat Genet 2001;29(1):66-9.

7. Klein C, Brin MF, Kramer P, Sena-Esteves M, De Leon D, Doheny $\mathrm{D}$, et al. Association of a missense change in the D2 dopamine receptor with myoclonus dystonia. Proc Natl Acad Sci U S A 1999;96(9):5173-6.

8. Leung JC, Klein C, Friedman J, Vieregge P, Jacobs H, Doheny D, et al. Novel mutation in the TOR1A (DYT1) gene in atypical early onset dystonia and polymorphisms in dystonia and early onset parkinsonism. Neurogenetics 2001;3(3):133-43.

9. Dürr A, Tassin J, Vidailhet M, Durif F, Jedynak P, Agid Y, et al. D2 dopamine receptor gene in myoclonic dystonia and essential myoclonus. Ann of Neurol 2000;48(1):127-8.

10. Grimes DA, Han F, Lang AE, St George-Hyssop P, Racacho L, Bulman DE. A novel locus for inherited myoclonus-dystonia on 18p11. Neurology 2002;59(8):1183-6.

11. Han F, Racacho L, Lang AE, Bulman DE, Grimes DA. Refinement of the DYT15 locus in myoclonus dystonia. Mov Disord 2007;22(6):888-92.

12. Hedrich K, Meyer E-M, Schüle B, Kock N, De Carvalho Aguiar P, Wiegers K, et al. Myoclonus-dystonia: detection of novel, recurrent, and de novo SGCE mutations. Neurology 2004;62(7):1229-31.

13. Foncke EMJ, Bour LJ, Speelman JD, Koelman JHTM, Tijssen MAJ. Local field potentials and oscillatory activity of the internal globus pallidus in myoclonus-dystonia. Mov Disord 2007;22(3):369-76.

14. Kuperman S. Tics and Tourette's syndrome in childhood. Semin Pediatr Neurol 2003;10(1):35-40.

15. Koskiniemi M, Donner M, Majuri H, Haltia M, Norio R. Progressive myoclonus epilepsy. A clinical and histopathological study. Acta Neurol Scand 1974;50(3):307-32.

16. Chinnery PF, Reading PJ, McCarthy EL, Curtis A, Burn DJ. Lateonset axial jerky dystonia due to the DYT1 deletion. Mov Disord 2002;17(1):196-8.

17. Kabakci K, Hedrich K, Leung JC, Mitterer M, Vieregge P, Lencer $\mathrm{R}$, et al. Mutations in DYT1: extension of the phenotypic and mutational spectrum. Neurology 2004;62(3):395-400.

18. Leuzzi V, Carducci C, Carducci C, Cardona F, Artiola C, Antonozzi I. Autosomal dominant GTP-CH deficiency presenting as a dopa-responsive myoclonus-dystonia syndrome. Neurology 2002;59(8):1241-3.

19. Stamelou M, Mencacci NE, Cordivari C, Batla A, Wood NW, Houlden $\mathrm{H}$, et al. Myoclonus-dystonia syndrome due to tyrosine hydroxylase deficiency. Neurology 2012;79(5):435-41.

20. Angelini L, Erba A, Mariotti C, Gellera C, Ciano C, Nardocci N. Myoclonic dystonia as unique presentation of isolated vitamin $\mathrm{E}$ deficiency in a young patient. Mov Disord 2002;17(3):612-4. 
21. Kurlan R, Behr J, Medved L, Shoulson I. Myoclonus and dystonia: a family study. Adv Neurol 1988;50:385-9.

22. Fahn S, Sjaastad O. Hereditary essential myoclonus in a large Norwegian family. Mov Disord 1991;6(3):237-47.

23. Cif L, Valente EM, Hemm S, Coubes C, Vayssiere N, Serrat S, et al. Deep brain stimulation in myoclonus-dystonia syndrome. Mov Disord 2004;19(6):724-7.

24. Gruber D, Kühn AA, Schoenecker T, Kivi A, Trottenberg T, Hoffmann K-T, et al. Pallidal and thalamic deep brain stimulation in myoclonus-dystonia. Mov Disord 2010;25(11):1733-43.

25. Azoulay-Zyss J, Roze E, Welter M-L, Navarro S, Yelnik J, Clot F, et al. Bilateral deep brain stimulation of the pallidum for myoclonusdystonia due to $\varepsilon$-sarcoglycan mutations: a pilot study. Arch Neurol 2011;68(1):94-8.

26. Blackburn JS, Cirillo ML. Clinical reasoning: A 13-year-old boy presenting with dystonia, myoclonus, and anxiety. Neurology 2012;78(11):e72-6.

\section{Big opportunities.... small communities await!}

Guysborough Antigonish Strait Health Authority serves a population of just under 44,000 residents in Antigonish, Guysborough, Inverness and Richmond counties in picturesque Nova Scotia. Our district includes five healthcare facilities in Antigonish, Canso, Guysborough, Evanston and Sherbrooke. We also have services relating to Primary Health Care, Continuing Care, Addiction Services, Mental Health and Public Health. GASHA is home to St. Francis Xavier University, a campus of the Nova Scotia Community College and has the first accredited District Trauma Centre in Nova Scotia.

Living and working in rural Nova Scotia comes with many benefits. Smaller communities mean closer relationships with fellow physicians, staff and local residents while still maintaining close proximity to the major centres within the province. Provincial incentives are available for physicians working within GASHA. We invite you to come and check out our lifestyle. You will not be disappointed!

\section{Contact:}

Dr. Jeremy Hillyard, Vice-President, Medicine

GASHA 9028674500 ext 4710 jeremy.hillyard@gasha.nshealth.ca

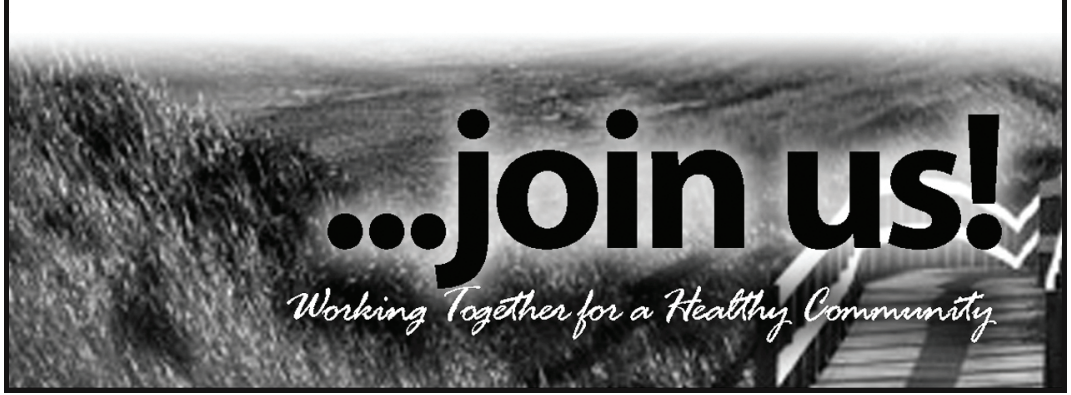

